\title{
Intelligent Technology to Enhance Policing and Public Accountability
}

\author{
Aloísio Vieira Lira Neto ${ }^{1,2}$ \\ ${ }^{1}$ Brazilian Federal Highway Police, Fortaleza/CE, Brazil \\ Email: aloisio.lira@prf.gov.br \\ ${ }^{2}$ University of Fortaleza, Fortaleza/CE, Brazil \\ *Corresponding Author: , Email: aloisio.lira@ prf.gov.b
}

How to cite this paper: Neto, Aloísio V. Lira (2021) Intelligent Technology to Enhance Policing and Public Accountability. Journal of Artificial Intelligence and Systems, 3, 48-67.

https://doi.org/10.33969/AIS.2021.31004

Received: January 15, 2021

Accepted: February 19, 2021

Published: February 24, 2021

Copyright $@ 2021$ by author(s) and Institute of Electronics and Computer. This work is licensed under the Creative Commons Attribution International License (CC BY 4.0).

http://creativecommons.org/licenses/by/4.0/

\section{Open Access}

\section{Abstract}

In view of the situation of violence faced in Brazil, several actors, from the most diverse areas of knowledge, have been dedicated to studying, analyzing and proposing solutions for public security. The great challenge of much of what is produced is to combine theory with practice. In addition, the fact that we do not have State policies, but Government policies contribute significantly to the lack of long-term studies. Discontinuities, whether due to the ineffectiveness of what is proposed, or due to cultural and organizational changes in crime, preclude a cycle of planning, execution, evaluation and correction. This brings us to the first observation of modern public security: volatility. Thus, it is impossible to imagine modern management without the use of technology for the quick and assertive analysis of the problems faced. In this sense, the use of the intelligence, strategy, and technology triad becomes essential for accurate monitoring of these changes, providing guidelines and subsidies for the modernization of public security management and security and policing matrix. Given these statements, the present study has the general objective of presenting the Policy to Combat the Mobility of Crime and its effects on the Public Security of the State of Cear[Pleaseinsert"PrerenderUnicode-"intopreamble] (Brazil), referring to the period from 2017 to 2019. Through an empirical analysis, statistical data were collected to present a direct scenario of the implementation and the results achieved and present the theoretical relationship between the actions and the results, thus providing an exploratory depth of the facts and their impacts. In order to show the positive results achieved, a quantitative and qualitative method was used to correlate aspects and concepts in the large area of the humanities with practical policing and technological applications. As a result of the implementation of the Combating the Mobility of Crime, the State of Cear[Pleaseinsert"PrerenderUnicode-"intopreamble] managed to place the number of robberies and homicides among the lowest rates of the decade, gaining national prominence of strategy and technology employed. Thus, the Policy to Combat the Mobility of Crime changed the policing matrix, allowing greater efficiency of the resources used and better monitoring the indicators.

\section{Keywords}

Expert Systems, Intelligent Systems, Crime Mobility, Indicative Police System Approach, Territorial Protection and Risk Management Program, Public Security Strategy. 


\section{Introduction}

The increasingly rapid and frequent transformations in society, caused mainly by technological advances and universal access to information, made many public management models practiced in Brazil and the world lagged.

This gap can be seen in several administration sectors, including public security, where the almost exclusive use of quantitative indicators for measuring success is predominant [38].

The guarantee of public security has always been a challenge for governments throughout history; it is no different in Brazil. Over the past decade, we have monitored countless general security policies and policing models that have not been permanently effective in several states [33]. When taking over management, each government implemented a new project with large investments in marketing, but with little or no applicability and sustainability methodology. As a result, although some initial results have been achieved, violence soon returned to earlier or worse levels [11].

In the theoretical and practical spheres, what is observed is the inexistence of a welldefined scope of competencies or adequate management tools for effective control of what is carried out, making it extremely difficult to manage public security policies in execution. This deficiency causes room for policies without evidence or a model of trial and error [33].

For this reason, more than seeking successful models or cases, it is essential to foster academic research, which should be oriented towards improving the use of available resources $[24,12]$.

A brief survey conducted on the application of policing in the last decade revealed that both the use of outdated statistical analysis as a parameter for the distribution of protection and the absence of a holistic view that sought to understand the temporal and spatial logic of each type of behavior crime Contributed enormously to the failure of public security policies [25].

The rapid capacity to adapt criminal behavior also stands out among the theme's managers' main difficulties, highlighting the need to maintain an organic plan. Police and other actions are updated with each newly identified conduct [18].

Practically all ostensive police in Brazil have widely used action planning guided by hotspots1. However, in specific applications in which can use this type of planning, this method's predominance for high crime mobility situations has generated several losses for society over time [37]. As described by Beato Filho [3], the managers who used this model witnessed migration or fractionation of criminal spots in smaller portions. As a direct consequence, although initially there is some result, it does not remain in the long term.

Therefore, the fractionation and migration of the spots generate a considerable increase in demands for other areas [1]. Notably, those that exercise intelligence activities, which, with a much higher operating cost and with limited resources, now assume the role of carrying out fieldwork to identify criminal groups operating in these areas [40].

It also appears that the motor vehicle is widely used in criminal practice, especially in crimes of theft and homicide, serving as a kind of catalyst for illegal activity. This fact emphasizes the need to understand and study the impacts of the motor vehicle's popularization and the evolution of urban mobility on public safety [16, 28].

The initial hypothesis, adopted in this study, points out that the increased use of the motor vehicle, from the 2000s onwards, generated two simultaneous effects: which strongly contributed to the increase in criminal activity. (1) criminal behavior, which was based predominantly in ambush, migrated to a model based on the use of windows of criminal opportunities, with motor vehicles' help; (2) policing, which was carried out on foot or horseback in communities, became almost entirely motorized.

As a result of factors (1) and (2), profound changes in the form of organization of society could be seen: the weakening of informal social control instruments and the accentuation of disorganization in communities. 
As policing migrated to motor vehicles, it was possible to observe a break in ties with society, formed by community or proximity policing models until then. This movement caused the police to be seen as beings that are strangers to the communities [9].

Thus, in an increasingly technological and volatile world, the need to update organizational paradigms becomes evident [20]. Reacting and adapting instantly to the population's behavioral changes is essential for providing quality public service [17].

Therefore, the use of the intelligence, strategy, and technology triad becomes essential for accurate monitoring of these changes, providing guidelines and subsidies for the modernization of public security management and the policing matrix [19].

In this sense, the present study has the general objective of presenting the Policy to Combat the Mobility of Crime and its effects on the Public Security of the State of Ceará, referring to the period from 2017 to 2019.

Given the following specific objectives: to highlight the transformations of society and the various factors that influenced the change in a criminal action, in particular, the Mobility of Crime; analyze the challenges imposed by social changes and their impact on the enforcement of policing; to present technologies and methodologies that can be used in policies to reduce violence and confront crime, especially Intentional Lethal Violent Crimes (ILVC) and Violent Crimes against patrimony (VCP); describe the elements that constitute the Policy to Combat the Mobility of Crime in the State of Ceará; expose the results of the application of the Policy to Combat the Mobility of Crime in Ceará.

It was based methodologically on empirical analysis, through the collection of statistical data, to present a direct scenario of the implementation and the results achieved. The criminal-statistical data come from the compilation of the numbers of criminal occurrences, carried out by the Statistics and Geoprocessing Management (GEESP / SUPESP / SSPDS$\mathrm{CE})$.

The research presents a theoretical relationship between the actions and the results, giving rise to an exploratory depth of the facts and their impacts. The complexity of public security and the multiple vectors that influence it must be considered when interpreting the results presented.

We used a quantity-qualitative method to show the results achieved in this case study, seeking to correlate aspects and concepts of the large area of human sciences with practical policing and technology applications.

\section{Theoretical Reference}

The theoretical framework was structured in 04 (four) main topics: the policing paradigm; the evolution of police work; urban mobility and the challenge of policing; crime mobility and statistical policing.

\subsection{The Policy Paradigm}

At the beginning of the 20th century, the predominant policing model was that of "political police," intended to serve only politicians' wishes, to the detriment of society's interests. Subsequently, this model was replaced by "professional police," which had the purpose of acting exclusively in places where crimes and violence were practiced, adopting the bureaucracy and technical training of its agents as the primary operating guideline.

Widely used today, the major problem that professional policing presents is that it completely ignores the citizen, concentrating its actions exclusively on social offenders' search. This behavior strengthens the idea that the offender's arrest is more important than maintaining order; providing assistance to people; monitoring the consequences of crimes; knowledge of the ways in which crime works; execution of differentiated actions to reduce violence such as urbanization; an improvement in social cohesion; among others [35]. 
The counterpoint that the need to modernize the police focus necessarily took place in the USA, in the 60s and 70s. Large protests against the war, in favor of civil rights and other social societies, ended up including police institutions, almost always in charge of repression, thus forcing the American authorities to rethink the policing model, intending the police towards a new model of action.

This situation made the American police authorities turn to universities for development in studies based on the population's revolt against the police, instead of supporting it. The finding of studies concluded that the police were seen as an alien entity to the communities, mainly because their presence was sporadic and with the use of police vehicles, without any contact with people, with values, or with local problems. Professional policing, still practiced massively in Brazil, proves to be inefficient, as the police are hardly able to reach the crime scene during the occurrences, thus making it one of the least suitable guardians to prevent crime from happening.

According to studies by Bayley [2], the police are the least qualified body to act preventively in most cases. This statement is mainly based on the fact that the police can hardly reach a crime scene during its execution. Among the various factors that contribute to this statement is that the criminal, now motorized, chooses the victim and the place where the success of his action is most likely. This allows a quick and precise action, in addition to facilitating their escape and concealment, right after the criminal act.

On the subject, Clarke and Felson [7] point out that the people best able to prevent a crime are not police officers (who are rarely around to discover crimes in the act). But neighbors, friends, relatives, onlookers, or the property owner, given that a criminal finds, in the absence of capable guardians, the exact moment to carry out the crime.

For Rolim [30], author of the work "The Syndrome of the Red Queen," in the actions in which the crime has already occurred, the quality of the service must be prioritized about the response time, according to the author, what is accepted widely, emergency response times only make sense for ongoing crimes. In such cases, of course, a prompt police response can have considerable effects. The whole problem is that this type of occurrence is not shared. What seems even more surprising is that the research already carried out on this topic appears to converge to the same kind of expectation of the victims who, at first, never have an immediate response from the police. They have said that they expect the police to offer them meaningful help, which points to the quality of the response and not the time it will be given.

It is well known that the reality faced today in large metropolises makes it impossible for the police to make a rapid cultural change, given that, according to police jargon, "they don't have time to breathe." Adapting policing on a large scale requires a large financial investment aimed at modernizing equipment and systems and training police officers and managers in public security [22].

The police are trapped in a cycle, described by Rolim [30] as the Red Queen Syndrome, alluding to the children's work "Alice in Wonderland," more specifically the part of the story where the main character, after running for a long time, he realizes that he is in the same place. This is the behavior of police officers in Brazil: there is a lot of running to keep crime rates at the same level, even if they are not acceptable levels. In the police environment, this movement is commonly compared to the act of "wiping ice," demonstrating the perception, even if superficial, of the flaws in the functioning paradigm [29].

Within this panorama, it is evident that it is necessary to change the dominant policing matrix currently in force. In order to achieve this goal, it is necessary to strengthen the understanding of the individual dynamics of crimes from a new perspective in relation to social factors, as well as to make use of available technologies and increasing investments in research [34].

This understanding allows the police to develop efficient work, based on a solid understanding of social phenomena and criminal behavior, with the least possible empiricism, always in search of technical evidence for support decision making, working 
from the perspective that your interventions must be surgical, under the risk of becoming a police state [10].

\subsection{Evolution of Police Work}

According to David H. Bayley [2], maintaining order is the essential function of government. Not only is the government's legitimacy largely determined by its ability to maintain order, but the ruling also serves as a criterion for determining whether there is any government at all. Both conceptually and functionally, government and order go together.

Historically, several factors have contributed to the changes in the patterns of operation and organization of the police. Among which we can mention: demographic growth; the increase in subnormal agglomerates, caused by the disorderly expansion of cities; the explosion of urban mobility, especially with the popularization of the motor vehicle; the expansion of the concept of community, due to the emergence of the internet and social networks; the increase in online fraud, mainly in purchases and improper transfers of financial resources; the rise of cryptocurrencies; increasing exposure to corruption; strengthening international trafficking, among others $[6,32]$.

There are several scenarios, some new and others in which the criminal conduct has specialized and evolved, which impose daily challenges to public security, especially about police training. This diversity has led police institutions to start specialization work to address the gaps that have emerged over the years. However, in most cases, there is no idea of the problem's size, as in the sphere of cybercrimes, for example, where underreporting prevails [39]. Adapting police culture to the new public security challenges has been a significant challenge. Violent crimes against the person and property, for example, had a substantial growth due to the act's facilitation and the increase in efficiency, provided by the use of the motor vehicle, as evidenced in the discussion of the results.

Even today, the police matrix operates, predominantly, guided by a logic of criminal stain; however, with the current ease of access to means of transport, which contribute significantly to the increase in crime mobility, this cannot be the only parameter adopted to direct policing.

According to police experience, it is observed that it is common sense that before crimes that happened in deserted and dark places started to occur in broad daylight: at street corners, bus stops, traffic lights, congestion, or any other site that, due to its territorial characteristics, it favors the use of some criminal opportunity.

According to Beato Filho [3]: One of the answers to the inefficiency in this patrolling style is that it is allocated according to the police organization's logic, not with the spatial and temporal dynamics of criminal crimes. Resources are given in response to the number of events that have already occurred in the areas of policing. However, a more detailed analysis regarding the incidence of these crimes would easily show how different dynamics exist for each occurrence, with common characteristics that can be identified.

The offenders' adoption of this new model of action, which has mobility as its matrix, caused an exponential increase in criminal acts' success rate and an accelerated gain of expertise. These attractions were sufficient for the offenders, especially young people, to migrate quickly to this behavior pattern. The vehicle, therefore, became a kind of catalyst for crime.

Thus, we can say that urban mobility had a significant impact on the increase in crime and social behavior, decreasing informal social coercion factors, as it weakened community ties, resulting in social disorganization. These corroborate the pressing need to make profound changes to current policing models. In this work, we conceptualize this phenomenon as "Mobility of Crime." 


\subsection{Urban Mobility and the Policing Challenge}

The evolution and cheapness of motor vehicles, especially automobiles and motorcycles, and large cities' uncontrolled growth triggered a social organization restructuring. Thus, urban mobility significantly affected the power of informal social coercion, the main factor of social control and reduction of violence, reducing the habit of community coexistence such as conversations on the sidewalks and local businesses' use, leaving the streets more deserted.

These factors, added to those already known by public security operators: such as reduced staff, limited technology available to the police, few continuing education programs, low investment in general security, among others, caused a change in the modus operandi of crime, culminating in current levels of violence.

The large and growing areas that needed policing instead of the reduced number of police officers brought about profound changes in police work. The solution found was the migration from patrolling on foot, from proximity to the motorized one, creating a distance from the communities To cover larger regions with the same number of servers.

In this new model established, the police were overwhelmed and unable to promptly meet the massive demands for crimes. Also, the isolated and uncoordinated actions of the various public security bodies and the absence of individual macro objectives and, much less, in common, contributed to a real confusion that was established. Therefore, it is evident that it is not enough to arrest and recover stolen products or hire more police officers and buy more vehicles and weapons. A structured crime reduction policy is necessary, which results in a reduction in violence [23].

In this context, the concept of Mobility of Crime aims to understand the impact of increased urban mobility, especially the popularization of the motor vehicle, on society and the police's criminal and organizational behavior, which is also organized from the perspective of mobility. And it needs a correct criminal analysis for the development of assertive models of action [26].

The following will detail evidence in theories and concepts widely used by police in the world to contextualize, with theoretical bases, this need for change in the policing matrices currently practiced.

\subsubsection{Theory of Routine Activities and the Windows of Criminal Opportunities}

The Theory of Routine Activities, by Cohen and Felson [8], explains the "crime triangle" by listing three main factors for the commission of an offense: (1) a motivated aggressor, (2) a victim in vulnerable conditions, and ( 3 ) a suitable location. For many years, this concept has been used to plan ostensible ordinary policing through the famous criminal spots, which adopts the variable "appropriate place" to try to prevent crime.

However, it appears that with the current ease of access to means of transport, the applicability of this system has become obsolete for most criminal practices, especially violent ones. The crime, which used to happen in deserted, dark places or with few people on the streets, started to occur in broad daylight, at bus stops, at traffic lights, in traffic jams, in several other places.

According to Beato Filho [3], this logic of organization of policing does not bring a detailed analysis of the crimes, nor does it take into account several factors such: the maintenance of order; providing assistance to people; monitoring the consequences of crimes; knowledge of how corruption works; among others.

The use of the vehicle, notably motorcycles, allowed social offenders to gain great mobility, taking advantage of a condition called "Windows of Criminal Opportunities". In short, these windows correspond to the ability that criminals have acquired to quickly find the best opportunity, the one that has the greatest chance of success, commit the criminal act and run away, to hide immediately afterwards. 
In this way, the behavior of the offenders who, before the popularization of the motor vehicle, resembled ambushes, in their execution mode, where the offender chose a deserted place and waited for a victim in vulnerable conditions, gave space to actions that use mobility as a weapon and enhancer of success.

In its execution mode, which refers to irregular combat actions, we define the "Window of Criminal Opportunity," the creation, by the offender, of a condition of crime. Thus, he started to carry out tactical assessments, immersion processes, including in policed locations, to better assess the territory; rapid and accurate executions of robberies, homicides, and other crimes. Right after the criminal practice, undertake escape, taking advantage of the high mobility provided by motor vehicles and urban camouflage, favored by a large number of circulating vehicles and the number of similar cars [21]. These changes, which occurred in the way criminals acted, caused real chaos in public security, forcing the police to work on a diffuse reactive model, which has had little success in preventing and repressing certain types of crime. Although the migration to motorized policing, police action is still guided by a static spatial logic, which causes an inadequate response, as described by Beato Filho [3].

The speed at which the transformation of criminal behaviors took place did not allow the State's little-mobile and archaic structure to adapt, making policing systems based on illegal spots obsolete. The attackers started to create security windows. Opportunity to commit a crime and migrate from the region, whenever protecting was adapted. With mobility and maneuverability for victims' choice, armament became secondary, since, in certain situations, only the offender's physique is sufficient for the success of the criminal activity.

This conjuncture is very similar to the contexts in which irregular combat practices occur: which consists of confronting large military forces, carried out by small, extremely organized groups that, despite having less firepower, have excellent mobility and agility in the execution of actions unconventional indirect combat.

\subsubsection{Economic Theory of Crime and Rational Choice}

Several motivations lead a person to commit crimes. Gary S. Becker, the winner of the 1992 Nobel Prize in economics, proposed the "Economic Theory of Crime" [4], which contemplates several economic models to explain crime. These have since been used on a large scale to help formulate public security policies in various parts of the world.

In 1968, Becker published the article "Crime and Punishment: An Economic Approach," [4] published in the Journal of Political Economy, in which he uses economic reasoning to explain that the execution of the criminal act is a rational choice, where the author assesses several variables involved and costs gave the possible profit to be obtained.

According to Cerqueira and Lobão [5], in the text "Determinants of crime: theoretical frameworks and empirical results": The decision to commit the crime or not would result from a process of maximizing the expected utility. In which the individual would confront, on the one hand, the potential gains resulting from the criminal action, the value of the punishment, and the associated probabilities of detention and imprisonment, on the other, the opportunity cost of committing crimes, translated by the alternative salary in the labor market.

This theory explains a large part of criminal behavior because it translates, logically and rationally, the reasons for committing crimes. Thus, Becker [4] briefly states that the social offender evaluates the costs and possible profits of the action to decide whether to commit the crime.

Adopting this logic and analyzing what we discussed in the previous topic, on the Theory of Routine Activities, we can intuitively understand the exponential increase in crime. With the execution and escape facilitated by motor vehicle vehicles' use, the "cost" to commit the crime, that is, the possibility of being arrested during or after the crime was committed, fell dramatically. Also, with the repetition of actions and the natural evolution of expertise, the "cost" is reduced with each new criminal practice based on accumulated knowledge. The 
combination of these factors has made illegal activity more and more attractive over time.

As a result, motor vehicles, especially automobiles and motorcycles, have become primary inputs of criminal practice. Both for the ease of arrival and escape from the places where the crime is carried out. also for the fact that the vehicle can be sold to gangs that specialize in cutting and cloning or be used to carry out other crimes such as drug trafficking.

This economic reasoning shows that a policy aimed at controlling urban movement and combating theft and cloning vehicles would achieve good results, such as those obtained in Ceará between 2017 and 2019. The explanation for this is that this model directly contributes to reducing Crime Mobility. Thus, by producing negative impacts on the primary potential fuel for criminal actions - motor vehicles -,, we have the consequence of a chain reduction of all crimes that use this means for their execution.

\subsubsection{Urban Mobility, Coercion and Social Disorganization}

According to Clifford Shaw and Henry MacKay's Theory of Social Disorganization [36], social order, stability, and integration of communities contribute to social control and compliance with laws. When present in these groups, cohesion creates informal social coercion and the existence of empathy among its members, resulting in a low incidence of violence. The low criminal incidence, in turn, allows for moral, social development, which feeds back into the cohesion process, strengthening the maintenance of peace and harmony.

Crime Mobility has had complex effects on society, especially on public security. Removing citizens from the streets and community life enabled the development of criminal groups in areas that were previously considered peaceful and safe, including policed ones. Situations in which residents of the same street, even neighbors, did not know each other became common.

With the increase in the feeling of insecurity, there was a drastic decrease in local social coexistence and empathy among community members. This fact produced a substantial weakening of informal social coercion. It caused a great deal of social disorganization in the communities, which caused the Newman Defensive Space [27] mentioned by SABOYA [31] to decrease, directly impacting the increase in crime.

The increase in urban mobility also contributed to this situation. It caused significant changes in the social routines of using supermarkets, pharmacies, bakeries, squares, and other leisure options and services in general. These places, which were once meeting points for residents of the neighborhood and, often, served as an environment for discussions of community problems and approximation among its members, creating empathy and a feeling of local defense, have ceased to have this function.

As already mentioned, the growth of social disorganization weakens informal social controls, such as the family, religion, school, and other groups, institutions, and associations that preach social well-being, thus facilitating young people's recruitment the increase in violence rates. Another factor resulting from the increase in the Mobility of Crime is the decrease in sidewalk areas (sidewalks) by residents. As a result, there was a significant reduction in commuting on foot and in the old habit of sitting in chairs on the sidewalks to talk. The fear of being stolen by an offender using a vehicle is among the leading causes of this transformation.

Several city halls have developed actions to encourage the occupation of public spaces to reduce these impacts. Among the ideas used are the implantation of shared bicycle stations, creating areas for fairs, programs of events in the neighborhoods, and others. Despite these efforts, in most cities, walking is still seen as risky by a large part of the population, mainly because of being the victim of theft. Cities have implemented CONSEGs (Community Security Councils) in communities. They have had positive results in reducing violence but continue to suffer from crimes committed by offenders from other locations who use vehicles to commit such crimes.

Implementing policies to control vehicle movements, in conjunction with the 
strengthening of actions to combat theft and cloning of vehicles, would significantly reduce crimes committed by offenders in other regions. With this, the community would start to worry about internal violence, almost exclusively easier to control due to the residents' easy recognition of the aggressors themselves. This environment would make it possible for people to return to public spaces, creating a virtuous security cycle.

\subsubsection{Differential Association and Youth Grooming}

Edwin Sutherland's Differential Association Theory, in short, consists of delinquent behavior as a result of social learning, where the offender often lives with patterns of behavior that foster the violation of laws and, from that, takes for himself values that overlap the compliance with the law.

What draws attention in Mobility of Crime is that the vehicle enhances the possibilities of successful criminal actions, creating a strong feeling that the offender is unlikely to be arrested. For this reason, the young person who often lives with criminals absorbs this "implicit message." At this point, many young people begin to assess costs and gains (as we have already discussed in the Economic Theory of Crime) and see theft as an advantageous profit option.

Here, finally, we come to the tipping point of crime. Under normal conditions, the criminal would begin committing crimes without much knowledge, acquiring experience slowly. He dedicated more crimes, thus being due to the risk of making gross errors, which is entirely exposed to the police. With the ease provided by the use of vehicles, gangs began to multiply more quickly. The "newbies,": who start as mere participants, having no roles that can hinder the execution of actions, become, in a short time, capable of executing crimes and recruiting new young people, usually their friends from the closest cycle, thus creating the vicious cycle that resulted in the explosion of crime.

Therefore, the importance of the motor vehicle is due to the excellent probability of success it offers and the profit it provides, since it facilitates the choice of victims with more resources and, in the last case, can quickly sell it. With that, this type of criminal starts to have an image of success in the communities, just as it already happens with the drug dealer, making it even easier to attract young people searching for status in the same community. The prevalence of this stereotype in these regions subverts the concept of right and wrong in the view of young people who do not yet have fully consolidated moral values, generating even more violence and non-compliance with the laws.

\subsection{Crime Mobility And Statistical Policing}

As explained earlier, there may be several factors and motivations for criminal practice. Despite the need to deepen in each of them, it is part of acceptable management practices to build a matrix of gravity, urgency, and tendency (GUT): which helps in the definition of action priorities, making it possible to deal with the most impacting situations, that is, more damaging, first [15].

Based on this logic, using knowledge about the concept of Mobility of Crime, theft, and adulteration of vehicles are among the most severe criminal conduct in the contemporary public security scenario. This fact is because, as we exemplified earlier, the car acts as a kind of catalyst for the commission of several other crimes, facilitating criminal practice and causing disorganization in policing.

The changes in criminal behavior, which started to use the Windows of Opportunity, associated with the uncontrolled growth of cities, put into question the models of statistical policing practiced until then, showing the economic unfeasibility of maintaining a large enough force to saturate all areas where crimes occurred. Thus, the police response began to operate in a diffuse logic: there is no plan to deal with the causes of the problem [14]. 
Figure 1 presents the isochronous map (Figure 1) of criminal conduct to exemplify the maneuverability that we describe in the Mobility of Crime. We have two points that correspond to sensors integrated into the Indicative Police Approach System - SPIA2. The monitored vehicle was used to commit an offense: it took about 5 minutes to move between points 1 and 2, having already counted the time necessary to execute the crime.

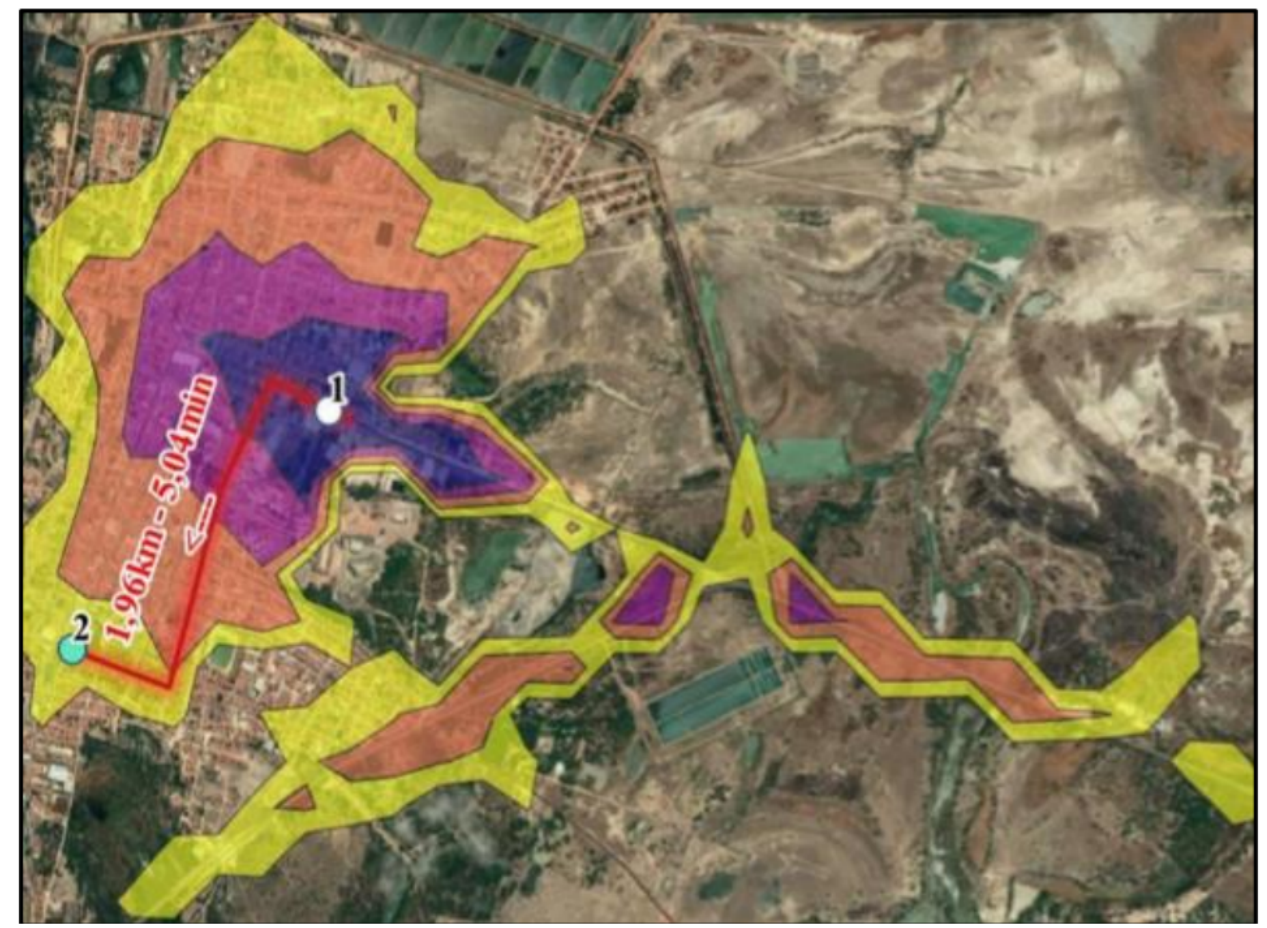

Figure 1. Isochronous map of actual criminal conduct that occurred in 2018 in the municipality of Aracati / CE SUPESP (2019).

The isochronous map used considers the average distance that can be reached, assuming a fixed time, from the passage at a certain point. Thus, endowed with good mobility and maneuverability, starting from point 1 , and taking into account the 5 minutes used to commit the crime and escape. The offender Could commit the offense anywhere on the isochronous map, colored area of the map that corresponds to $7.66 \mathrm{~km}^{2}$.

Analyzing the presented map and the area that comprises the "Criminal Opportunity Window," It is not possible to state, even with a well-elaborated statistical model, that a vehicle positioned at a certain point would be able to prevent the crime from being committed [13].

Even observing policing in several places, the offenders could move around the city quickly until they found a citizen in a vulnerable situation when they would then commit the crime. We are not saying that the police presence does not prevent crime, but demonstrating the limitations of this prevention model, given the changes in the modus operandi of crime.

Thus, observing the maneuverability capacity that the offender has using the motor vehicle, working policing in a static matrix means always being late about the criminal activity.

\section{Results and Discussions}

The main results achieved by the Policy to Combat the Mobility of Crime are evidenced by the reduction of violence and the confrontation of crime, especially Intentional Lethal 
Violent Crimes (ILVC) and Violent Crimes against patrimony (VCP) in the State of Ceará in the period of 2017 to 2019 .

\subsection{Crime Mobility combat Policy}

To face the challenge of implementing a current policy based on evidence and police organizations' cultural learning, the State of Ceará began to rethink its Public Security strategy, adding more technology and scenario intelligence to its business processes. In this sense, the first project implemented was the Policy to Combat the Mobility of Crime, based on the Concept of Mobility of Crime - CMC.

The concept starts from the premise that mobility is a central point for the police and offenders. Can verify this by observing that, according to the scenario, policing is carried out on foot, by bicycle, on horseback, or motorized. In the same way, crime is organized based on mobility criteria, with the environment, and access to vehicles, preponderant factors for the execution of most crimes.

The CMC was born from the first observation of criminal behavior, in which it was found that there was a greater concentration of crimes against life in low areas of the city, places that generally lack a more significant presence of the State, and that present a marked degradation of the urban space

The concept of crime establishes two main typifications about mobility: (1) crimes with territorial characteristics, those in which criminal spots have a more excellent permanence over time, and over which traditional models of motorized policing have little or no direct impact. (2) and crimes related to mobility and opportunity, which have no objective relationship with the place where they are carried out and where policing models guided by statistics have low effectiveness.

When it is said that mobile policing in places with spatial permanence of crimes, especially in areas of crimes against life, has little impact on containment and reduction, we are talking about routine policing and not saturation models as in some operations. This clarification is necessary, given that saturation operations can have effects, usually temporary, while the action lasts. However, it must emphasize that the police do not have enough staff to use this tactic massively in all critical mapped areas, especially in low states, such as Ceará.

To address these identified issues, the Crime Mobility Combat Policy - CMCP adopted three main guidelines for developing strategic actions and projects, two pioneering and a more traditional third, all aimed at improving the effectiveness of police work.

The first guideline refers to using technology to improve the response model to crimes considered to be mobility. The second concerns proximity policing strategies and their conceptual variations to reestablish control in territories deemed critical and strengthened the State's presence and partnership with citizens. The third and last guideline, which is not the scope of this study, refers to using cutting-edge technology to improve investigation, police intelligence, and the control and audit of the Secretariat of Public Security and Social Defense processes and projects of the State of Ceará - SSPDS.

Integration was carried out between the Public Security Secretariat of the State of Ceará and the Federal Highway Police of Ceará To meet the first CMCP guideline. This partnership, formalized in 2017, is based on 03 (three) pillars: (1) The Police Approach Indicative System (SPIA), which consists of artificial intelligence that integrates several sensors and cameras scattered throughout the city and can locate vehicles involved in crimes, in real-time; (2) The creation of intelligent enclosures by the operators of the Integrated Coordination of Security Operations - CIOPS, who, upon receiving the location of suspicious vehicles by SPIA, through the video monitoring system, guide the cars for the siege and capture work; (3) And the increase in the number of police officers on motorcycles (self-policing), strengthening the mobility of the Military Police when responding to incidents, resulting in reduced response times to incidents. 
This symbiosis between man and technology, which has a similarity with industry 4.0, was crucial for achieving good results. As can be seen in the following topics, in Figures 2 and 4: The State of Ceará has been reducing vehicle thefts and thefts in general noticeably since 2018, when the system started to operate with a more significant number of sensors and cameras.

The CMCP demonstrates that by "breaking" the "mobility of the criminal," its range of action becomes increasingly restricted, being limited to the vicinity of his residence or place where he is homing, facilitating the planning and concentration of policing strategic locations.

It was necessary to wait for the consolidation of the first strategy so that it was possible to implement the action strategy related to the second guideline. It was mandatory to break offenders' maneuverability not to expose policing on foot to sneak attacks based on mobility. After this stage, implemented the Territorial Protection and Risk Management Program PROTEGER.

PROTEGER consists of a broad response in public security, involving several State and organized civil society actors, who start to work together in areas with urban and socioeconomic vulnerabilities, in line with police actions. At first, this integration aims to contain criminal indexes through tactical combat by the police. Simultaneously, the other agencies and partners work to recover public spaces and direct social protection policies.

Spatial analysis work was carried out by the Superintendence of Research and Strategy for the State of Ceará - SUPESP. The incidence of homicides, the primary indicator, was correlated with 69 other socioeconomic indicators. To identify the main areas that should be initially attended and called Critical Areas of Public Security Interest - CAPSI.

PROTEGER, therefore, has as a premise the implementation of a model of proximity or proactive policing, based on semi-fixed bases that can have their locations adjusted, should the need arise. According to local particularities: the main characteristics can be listed as community policing's predominance on foot and support mobile policing teams in vehicles, such as cars, pickups, or motorcycles.

By focusing on people, the program aims to reduce violence, especially crimes against life, and strengthen ties between the state and the population. Among the main finalists' objectives sought is an increase in confidence in the state and a sense of security.

\subsection{Impacts and Results of the Crime Mobility Combat Policy}

In this work, for reasons of organic security, the methods and resources employed will not be addressed, being limited, the analysis to the impacts on the violence indicators of the Policy to Combat the Mobility of Crime.

Assessing the effects of public security policies is always a challenge. This difficulty is due to the numerous factors that directly or indirectly influence the results. For this reason, when investigating the impacts obtained, must take these variables into account.

Even in countries with relative stability in the context of public security, certain events can become the trigger for an increased sense of insecurity and movements of revolt against the State. Isolated facts, such as a police error, have the power to trigger strong social reactions. As happened with the death of the young African American Michael Brown's, in 2014, in Ferguson, in the State of Missouri, USA, generating a great wave of violence, civil unrest, and police demotivation. The impacts generated by this set of events were known as the "Ferguson Effect," this effect explains the detention and demotivation caused by the police after this type of repercussion.

The fear of acting established in the police then has negative impacts on public security. The same situation was repeated more recently, when, in May 2020, a white American policeman caused George Floyd's death, a black man, in Minneapolis in the state of Minnesota, USA. The commotion caused was such that demonstrations on American streets were still frequent two months after the event. 
From the context presented, what is widely accepted is that policing needs to be attentive to social and police culture to be useful in actions and seek to minimize errors and apply frequent cycles of reevaluation.

In this work, the main focus is on transforming the understanding of criminal activity and the paradigms of organization and police responses in an approach guided by the analysis of mobility and territories.

\subsubsection{Contextualization of the State Scenario of Public Security and the Results of Criminal Indexes}

In 2017, the most violent year in Brazilian history, 63,880 violent deaths were recorded, according to the Brazilian Public Security Forum, which corresponds to about 175 homicides per day. During this period, the Public Security Secretariat of the State of Ceará was changing management, and Secretary André Santos Costa was appointed earlier that year.

In May 2017, the State was hit by a wave of violence triggered by the dispute's intensification for spaces between criminal organizations that operated throughout the country. These events and their consequences contributed to what would become, in absolute numbers, the most violent year in Brazil's history.

In the State of Ceará, from April to May of the same year, the increase was almost 25\% in Intentional Lethal Violent Crimes - ILVC, presented in this study, which includes crimes of intentional homicide, femicide, injury followed by death and theft followed by the end (robbery). In the same period, the State broke records of increased vehicle thefts and Violent Crimes against patrimony - VCP, including all theft crimes, except robbery followed by death (stealing). In-vehicle theft increased by more than $36 \%$, from 841 to 1,149 , while the VCP increased by almost $28 \%$, from 6,026 to 7,707 .

What is observed is that, at first, all indicators were impacted by the intensification that occurred among criminal organizations, causing the impression that could treat the problem as one. The fact is that the temporal and spatial logic of these crimes is quite different. Although the vehicle is present in almost everyone, each type of infraction needs other answers as a support tool.

Given this scenario, in May 2017, the Policy to Combat the Mobility of Crime, which was still in the evaluation and improvement phase, had to be initiated. The first action taken was to reduce the mobility of criminals, with the implementation of the Indicative Approach Police System - SPIA, the strengthening of response routines, the Integrated Coordination of Security Operations - CIOPS, and the increased use of policing were crucial for this planning phase.

In the first month, even with few sensors integrated into SPIA's artificial intelligence, results related to the recovery of stolen, cloned, and tampered vehicles began to appear, contributing to a rapid reduction in vehicle theft and VCP rates. This fact is because the police now have an efficient model for prompt response and arrest of offenders.

Thus, we left a growing curve in vehicle theft and VCP indices to a decreasing one, as shown in Figure 2 and 4, respectively.

The impacts generated by the adoption of the CMCP, coupled with the other investments made by the State Government of Ceará, in salary improvements and staff growth, contributed to a reduction from 11,133 vehicle theft incidents in 2017 to 9,319 in 2018, more than a $16 \%$ decrease. In 2019 , this number dropped to 5,128 occurrences, resulting in a reduction of almost $45 \%$ to 2018 . If based on the year 2017, the decline was from 11,133 events to 5,128 . In 2019 , which corresponds to a nearly $54 \%$ reduction in the number of vehicles stolen in the state.

Figure 3 shows details by month over the years, showing that May and June 2017 were the peak of occurrences, highlighted in dark red, followed by months in light red, in the same year, and spaced in other years. The best results in dark green color occur in all months of the year 2019, showing the effectiveness of adopting the CMCP in this indicator. 


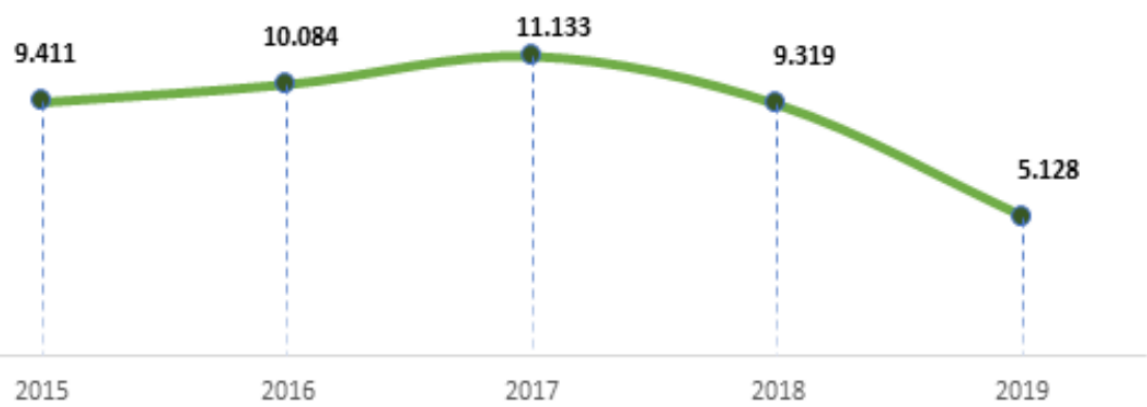

Figure 2. Number of occurrences of Vehicle Theft in Ceará, from 2015 to 2019. SUPESP (2020).

\begin{tabular}{|c|c|c|c|c|c|}
\hline Month & 2015 & 2016 & 2017 & 2018 & 2019 \\
\hline January & 906 & 756 & 824 & 891 & 407 \\
\hline February & 718 & 789 & 724 & 794 & 405 \\
\hline March & 804 & 918 & 886 & 913 & 472 \\
\hline April & 853 & 832 & 841 & 816 & 442 \\
\hline May & 886 & 1.010 & 1.149 & 860 & 429 \\
\hline June & 750 & 924 & 1.090 & 768 & 454 \\
\hline July & 778 & 754 & 950 & 696 & 401 \\
\hline August & 686 & 749 & 970 & 637 & 417 \\
\hline September & 687 & 805 & 956 & 699 & 356 \\
\hline October & 813 & 800 & 933 & 855 & 469 \\
\hline November & 754 & 871 & 924 & 728 & 444 \\
\hline December & 776 & 876 & 886 & 662 & 432 \\
\hline Total & 9.411 & 10.084 & 11.133 & 9.319 & 5.128 \\
\hline
\end{tabular}

Figure 3. Number of occurrences of Vehicle Theft in Ceará, from 2015 to 2019. SIP3W/GEESP/SUPESP/SSPDS-CE (2020). 
Likewise, the impact of VCP occurrences' total values can be seen in Figure 4, with 74,047 events in 2017 to 64,513 in 2018, a reduction of almost $13 \%$, and 49,579 occurrences in 2019, a decrease of about $23 \%$. If the period from 2017 to 2019 is considered, the decline reached 24,495 fewer recorded events, achieving a reduction percentage of around $33 \%$. In detail by month over the years in Figure 5, it is clear that May 2017 was the worst result of the period under analysis, highlighted in dark red, followed by the months in light red in the same year and spaced in other years. In contrast, the best results in dark green and light green occur in all months of the year 2019, showing the effectiveness of adopting the CMCP also in this indicator.

Regarding homicides, needed a specific model due to the particular logic of this type of crime. As mentioned, the intensification between criminal groups in 2017 also caused homicides to increase in Ceará, forcing the State to review its policing models.

As already discussed in this work, a study was carried out on the correlations between different social indicators and the incidence of homicides in the State; this product served as a basis to conduct the Territorial Protection and Risk Management Program - PROTEGER.

The implementation of the first bases was carried out in early 2018, still under evaluation, to support the decision to formulate a public policy. The installation was preceded by the police's intense tactical action, which aimed to pacify the most problematic territories.

From March 2018, according to data presented in Figure 6, a constant reduction in the monthly number of ILVC can be seen, ending the year with 4,518 occurrences, against 5,133 in 2017 , a decrease of 615 events, which represents an almost $12 \%$ difference. In

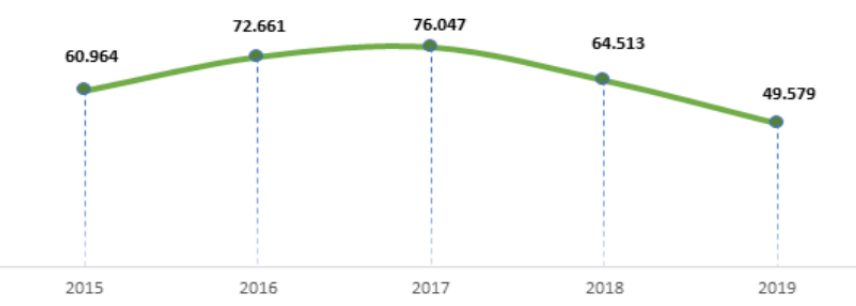

Figure 4. Number of occurrences of VCP in Ceará, from 2015 to 2019. SUPESP (2020).

\begin{tabular}{cccccc}
\hline Month & $\mathbf{2 0 1 5}$ & $\mathbf{2 0 1 6}$ & $\mathbf{2 0 1 7}$ & $\mathbf{2 0 1 8}$ & $\mathbf{2 0 1 9}$ \\
\hline January & 5.775 & 6.503 & 6.061 & 5.564 & 3.704 \\
February & 4.797 & 5.977 & 5.144 & 5.165 & 3.808 \\
March & 5.591 & 6.799 & 6.488 & 5.800 & 4.189 \\
April & 5.415 & 6.499 & 6.026 & 5.692 & 4.407 \\
May & 5.938 & 7.296 & 7.707 & 6.091 & 4.466 \\
June & 5.700 & 6.515 & 7.109 & 5.584 & 4.126 \\
July & 4.800 & 5.497 & 6.778 & 5.325 & 4.298 \\
August & 4.308 & 5.469 & 6.547 & 5.109 & 4.396 \\
September & 4.275 & 4.918 & 6.408 & 4.826 & 3.849 \\
October & 4.566 & 5.374 & 6.452 & 5.574 & 4.135 \\
November & 4.415 & 5.768 & 5.921 & 5.418 & 4.257 \\
December & 5.384 & 6.046 & 5.406 & 4.365 & 3.944 \\
\hline Total & $\mathbf{6 0 . 9 6 4}$ & $\mathbf{7 2 . 6 6 1}$ & $\mathbf{7 6 . 0 4 7}$ & $\mathbf{6 4 . 5 1 3}$ & $\mathbf{4 9 . 5 7 9}$ \\
\hline
\end{tabular}

Figure 5. Number of occurrences of VCP in Ceará, from 2015 to 2019. SIP3W/GEESP/SUPESP/SSPDS-CE (2020). 
2019, the program, already validated and implemented by the SSPDS-CE, had 29 bases installed, which, together with the policy of intervention in the prison system, carried out by Secretary Mauro Albuquerque, made the state end the year with 2,257 occurrences. This occurrence corresponds to a reduction of 2,261 deaths, a 50\% reduction. When Analyzing the accumulated variation between the years 2017 and 2019, it is possible to see that the State achieved a 56\% reduction in homicides, figuring as the federative unit with the most considerable reduction in the country and gaining prominence in the national media. Likewise, the detailed data by month also shows the peak of occurrences in the months of the year 2017, in the dark red color, while the best results are seen in the months of the year 2019, in the dark green color be seen in Figure 7.

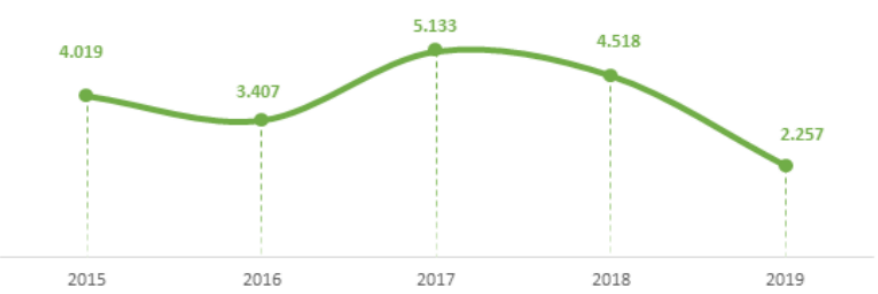

Figure 6. Number of ILVC victims in Ceará, from 2015 to 2019. SUPESP (2020).

\begin{tabular}{c|ccccc}
\hline Month & $\mathbf{2 0 1 5}$ & $\mathbf{2 0 1 6}$ & $\mathbf{2 0 1 7}$ & $\mathbf{2 0 1 8}$ & $\mathbf{2 0 1 9}$ \\
\hline January & 431 & 323 & 349 & 482 & 192 \\
February & 331 & 297 & 269 & 361 & 164 \\
March & 323 & 316 & 358 & 414 & 189 \\
April & 327 & 274 & 378 & 367 & 213 \\
May & 323 & 285 & $\mathbf{4 7 1}$ & 372 & 179 \\
June & 282 & 248 & 474 & 384 & 169 \\
July & 261 & 255 & 474 & 378 & 196 \\
August & 355 & 291 & 460 & 352 & 186 \\
September & 332 & 222 & 460 & 391 & 183 \\
October & 341 & 278 & 516 & 363 & 176 \\
November & 354 & 298 & 470 & 326 & 205 \\
December & 359 & 320 & 454 & 328 & 205 \\
\hline Total & $\mathbf{4 . 0 1 9}$ & $\mathbf{3 . 4 0 7}$ & $\mathbf{5 . 1 3 3}$ & $\mathbf{4 . 5 1 8}$ & $\mathbf{2 . 2 5 7}$ \\
\hline
\end{tabular}

Figure 7. Number of ILVC victims in Ceará, from 2015 to 2019. SIP3W/CIOPS/CPI/PEFOCE/GEESP/SUPESP/SSPDS-CE (2020).

Given the results presented above, it is possible to observe a temporal and spatial relationship between the Policy's implementation to Combat the Mobility of Crime and the results achieved in the State. It is strengthening the view that a policy based on mobility and territory, which considers the police and criminal behavior's logical organizational and cultural aspects, fits into a modern matrix of policing and police response.

\section{Conclusions}

In summary, we can identify that the concept of Mobility of Crime: based on several criminological theories, demonstrates that urban mobility, and especially the crime practiced with the use of the motor vehicle, causes profound social disorganization, greatly facilitating 
the criminal practice and generating attractive for the entry and stay of offenders in the world of crime. This conjuncture contributes to the increased feeling of insecurity, causing citizens to be absent from public spaces, creating a vicious cycle of factors that generate violence.

Society and the various bodies that make up the public security system were not prepared for the evolution of urban mobility. Can prove this fact by observing the maintenance of old practices based, almost exclusively, on repressive actions, by the police, and individualized residential protection by society, using electric fences and hiring surveillance services. Rare are the cases in which we can see organized community actions aimed at improving public security.

Another overriding factor is the need for the State to become more evident as an organizer, at least in the first instance, of communities. This urgency is due to the current occupation that criminals have been establishing in specific locations, making it impossible for the residents of these places to organize themselves as a community and start to defend their space.

The installation of full-time schools, squares, leisure and cultural spaces, sports and art schools, among others, are among the possible non-police actions that would increase the State's presence in communities, contributing to reduce violence in these places. A multidisciplinary understanding of each portfolio's responsibilities, which must act in an integrated manner to achieve public security objectives, is essential for the success of the policies developed; avoiding the establishment of an eminently police state security is the exclusive responsibility of the police.

The field of actions that contribute to the reduction of violence is vast. Still, this work's main scope is to show that a public security policy aimed at controlling vehicles and combating theft and cloning of cars would considerably decrease the Mobility of Crime, allowing for better use of policing and the self-determination of communities, promoting the social organization and compliance with laws.

Thus, the Policy to Combat the Mobility of Crime changed the policing matrix using technology and innovation to understand the phenomenon of contemporary crime better and respond in a more powerful way to this challenge. Way to improving and modernizing the application of policing allows greater efficiency of the resources employed and better monitoring the indicators.

\section{Acknowledgments}

VHCA received support from the Brazilian National Council for Research and Development (CNPq, grants no. 304315/2017-6 and 430274/2018-1).

\section{References}

[1] Metropolitan police. Engineering Technology, 1(2):57-57, 2006.

[2] David H Bayley. Padrões de Policiamento: Uma Análise Comparativa InternacionalCapítulo 2. Edusp, 2017.

[3] Cláudio C BEATO FILHO. Ação e estratégia das organizações policiais. In CONGRESSO DO PROJETO "POLÍCIA E SOCIEDADE DEMOCRÁTICA, volume 2, 1999.

[4] Gary S Becker. Crime and punishment: An economic approach. In The economic dimensions of crime, pages 13-68. Springer, 1968.

[5] Daniel Cerqueira and Waldir Lobão. Determinantes da criminalidade: arcabouços teóricos e resultados empíricos. Dados, 47(2):233-269, 2004. 
[6] Xiaoliang Che, Tanping Zhou, Ningbo Li, Haonan Zhou, Zhenhua Chen, and Xiaoyuan Yang. Modified multi-key fully homomorphic encryption based on ntru cryptosystem without key-switching. Tsinghua Science and Technology, 25(5):564-578, 2020.

[7] Ronald V Clarke and Marcus Felson. Routine activity and rational choice. new brunswick, 1993.

[8] Lawrence E Cohen and Marcus Felson. Social change and crime rate trends: A routine activity approach. American sociological review, pages 588-608, 1979.

[9] Clive Harfield. E-policing and the social contract. IEEE Technology and Society Magazine, 31(1):33-41, 2012.

[10] Roslin V Hauck, H Atabakhsb, Pichai Ongvasith, Harsh Gupta, and Hsinchun Chen. Using coplink to analyze criminal-justice data. Computer, 35(3):30-37, 2002.

[11] Jesse Hirsh. Predictive policing and civilian oversight: What will it take to get it right? IEEE Potentials, 35(5):19-22, 2016.

[12] P Hosmer. Use of laser scanning technology for perimeter protection. IEEE Aerospace and Electronic Systems Magazine, 19(8):13-17, 2004.

[13] Tanveer Hussain, Khan Muhammad, Amin Ullah, Zehong Cao, Sung Wook Baik, and Victor Hugo C de Albuquerque. Cloud-assisted multiview video summarization using cnn and bidirectional lstm. IEEE Transactions on Industrial Informatics, 16(1):77-86, 2019.

[14] Tanveer Hussain, Khan Muhammad, Amin Ullah, Javier Del Ser, Amir H Gandomi, Muhammad Sajjad, Sung Wook Baik, and Victor Hugo C de Albuquerque. Multi-view summarization and activity recognition meet edge computing in iot environments. IEEE Internet of Things Journal, 2020.

[15] Tanveer Hussain, Khan Muhammad, Weiping Ding, Jaime Lloret, Sung Wook Baik, and Victor Hugo $\mathrm{C}$ de Albuquerque. A comprehensive survey of multi-view video summarization. Pattern Recognition, 109:107567, 2021.

[16] E Ray Knickel and Albert W Van Horn. Improving police command and control with a patrol car emitter-call box sensor car location system. IEEE Transactions on Vehicular Technology, 19(2):178-184, 1970.

[17] Polychronis Koutsakis and Michael Paterakis. Call-admission-control and trafficpolicing mechanisms for the transmission of videoconference traffic from mpeg-4 and h. 263 video coders in wireless atm networks. IEEE transactions on vehicular technology, 53(5):1525-1530, 2004.

[18] Jean Kumagai. Techno cops [police robotic and electronic technology]. IEEE Spectrum, 39(12):34-39, 2002.

[19] Richard C Larson, Kent W Colton, and Gilbert C Larson. Evaluating a policeimplemented avm system: The st. louis experience (phase i). IEEE Transactions on Vehicular Technology, 26(1):60-70, 1977.

[20] Zheyu Li, Yongzhong Zhu, Hengliang Yang, Guohao Peng, and Xiaoyu Liu. A dualband omnidirectional circular polarized antenna using composite right/left-handed transmission line with rectangular slits for unmanned aerial vehicle applications. IEEE Access, 8:100586-100595, 2020. 
[21] Shuai Liu, Chunli Guo, Fadi Al-Turjman, Khan Muhammad, and Victor Hugo C de Albuquerque. Reliability of response region: a novel mechanism in visual tracking by edge computing for iiot environments. Mechanical Systems and Signal Processing, 138:106537, 2020.

[22] Josh Loeb. Algorithms on the beat: Ai and the future of policing. Engineering \& Technology, 13(4):26-30, 2018.

[23] Naercio Magaia, Ramon Fonseca, Khan Muhammad, Afonso H Fontes N Segundo, Aloisio V Lira Neto, and Victor Hugo C de Albuquerque. Industrial internet of things security enhanced with deep learning approaches for smart cities. IEEE Internet of Things Journal, 2020.

[24] Gary T Marx. The public as partner? technology can make us auxiliaries as well as vigilantes. IEEE Security \& Privacy, 11(5):56-61, 2013.

[25] Mohammed Muaafa and Jose Emmanuel Ramirez-Marquez. Engineering management models for urban security. IEEE Transactions on Engineering Management, 64(1): 29-41, 2016.

[26] Khan Muhammad, Tanveer Hussain, Muhammad Tanveer, Giovanna Sannino, and Victor Hugo C de Albuquerque. Cost-effective video summarization using deep cnn with hierarchical weighted fusion for iot surveillance networks. IEEE Internet of Things Journal, 7(5):4455-4463, 2019.

[27] Oscar Newman. Defensible space. Macmillan New York, 1972.

[28] Koichi Ogawa, Tomoki Uwano, and Masao Takahashi. A shoulder-mounted planar antenna for mobile radio applications. IEEE Transactions on Vehicular Technology, 49(3):1041-1044, 2000.

[29] David O'Reilly. Availability of required data to support criminal investigations involving large-scale ip address-sharing technologies. IEEE Security \& Privacy, 15(5):90-93, 2017.

[30] Marcos Rolim. A síndrome da rainha vermelha. Policiamento e segurança pública no século XXI. Rio de Janeiro: Jorge Zahar, 2006.

[31] Renato Saboya. Segurança nas cidades: Oscar newman e os espaços defensáveis, 2012.

[32] K Shankar, SK Lakshmanaprabu, Deepak Gupta, Ashish Khanna, and Victor Hugo C de Albuquerque. Adaptive optimal multi key based encryption for digital image security. Concurrency and Computation: Practice and Experience, 32(4):e5122, 2020.

[33] Kar Yan Tam, Yue Katherine Feng, and Michael C Lai. Effective use of policing systems: A two-stage study of the shakedown period of system implementation. IEEE Transactions on Engineering Management, 2019.

[34] Amin Ullah, Khan Muhammad, Javier Del Ser, Sung Wook Baik, and Victor Hugo C de Albuquerque. Activity recognition using temporal optical flow convolutional features and multilayer lstm. IEEE Transactions on Industrial Electronics, 66(12): 9692-9702, 2018.

[35] Jingjing Wang, Yiliang Han, and Xiaoyuan Yang. An efficient location privacy protection scheme based on the chinese remainder theorem. Tsinghua Science and Technology, 21(3):260-269, 2016. 
[36] Carlin Wong. Clifford r. shaw and henry d. mckay: The social disorganization theory, 2011.

[37] Hao Yin, Qiang Fu, Chuang Lin, Zhangxi Tan, Rang Ding, Yishu Lin, Yanxi Li, and Yanfei Fan. Mobile police information system based on web services. Tsinghua science and technology, 11(1):1-7, 2006.

[38] Wei Yuan, Pan Deng, Chao Yang, Jiafu Wan, Daqiang Zhang, Xiantong Chen, Chaofan $\mathrm{Bi}$, and Yali Liu. A smart work performance measurement system for police officers. IEEE Access, 3:1755-1764, 2015.

[39] Neng Zhou, Minqing Zhang, Han Wang, Yan Ke, and Fuqiang Di. Separable reversible data hiding scheme in homomorphic encrypted domain based on ntru. IEEE Access, 8: 81412-81424, 2020.

[40] Biaokai Zhu, Xinyi Hou, Sanman Liu, Wanli Ma, Meiya Dong, Haibin Wen, Qing Wei, Sixuan Du, and Yufeng Zhang. Iot equipment monitoring system based on c5. 0 decision tree and time-series analysis. IEEE Access, 2021. 